\title{
Effect Of Religiosity On The Household Women's Care-Giving Behaviour Towards The Elderly In The Family: A Case Of Sargodha City (Pakistan)
}

\author{
Mohammad Iqbal \\ Department of Social Work \\ University of Sargodha \\ Syeda Mehnaz Hassan \\ Department of Social Work \\ University of the Punjab
}

\begin{abstract}
This study was conducted with a purport to evaluate how far religiosity affects household women's care-giving behaviour towards senior individuals in the family. For this purpose, a random sample of 205 women of Sargodha city was selected from Sargodha City(Pakistan)to study the effect of religiosity on the General Well Being (as a measure of care) of the senior individuals in the family. The findings of the study indicate that mature women (41-50 years old) with moderate span of their married life (11-15years) give more care to the older adults in the family. But, despite that, a great majority of senior individuals in the family are at a state of low wellbeing level. The findings of the study revealed the reason that it was due to lack of religiosity which is strongly positively associated with well-being. Among the other factors, age, span of married life, household income and education correlate with the well-being positively but employment status negatively. Very interestingly, as the findings indicate, the care-giving behaviour is irrespective of the number of carerecipients in the family.
\end{abstract}

Key words: religiosity, general well-being, care-giving behaviour, elderly person

$$
\begin{aligned}
& \text { تلخيص }
\end{aligned}
$$

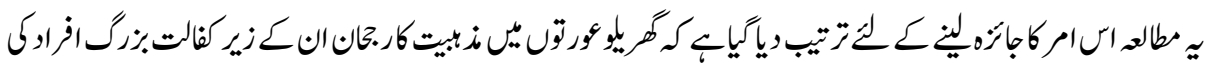

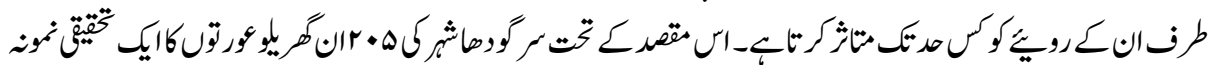

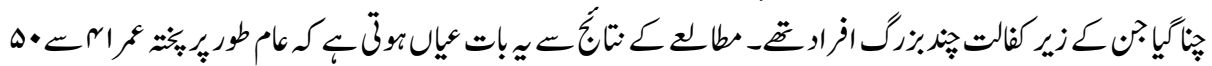

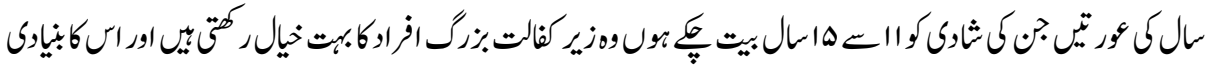

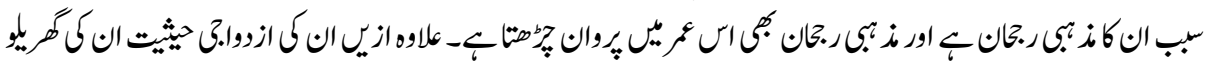

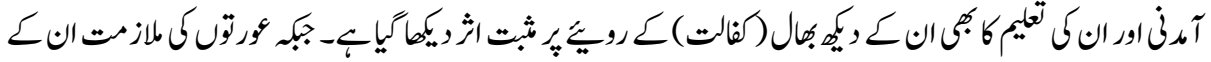

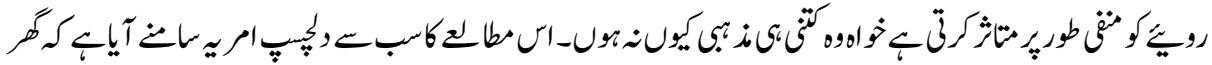

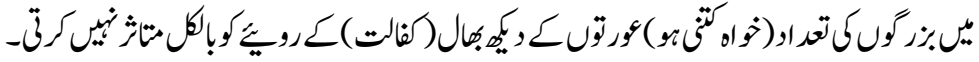

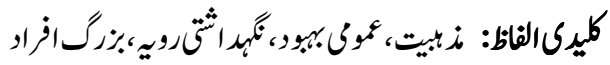



the Family: A Case of Sargodha City (Pakistan)

\section{Introduction}

Ageing is not a phase of life but a phenomenon (Wei and Sue, 2000; Wikipedia). Many factors help this phenomenon to occur in a peculiar manner. Main contributing factors are: economic conditions, health conditions, caloric intakes and previous social status of the senior individual (Cole and Winkler, 1994). All these factors play a decisive role in general well-being of the elderly (Birren and Shaie, 1985).

'General well-being' is a measure of gerontological care. It's a relative term. But researchers have harnessed its relativity through a wide consensus upon the fact that general well-being is the combination of feeling good and functioning good (Isaacowitz, 2005). If an elderly person successfully copes with nervousness; controls over his/her behaviour, thoughts, emotions, or feelings; is not sad, discouraged or hopeless; and is happy, satisfied, or pleased with his/her personal life is usually said to be in a state of general well-being (Noelker and Harel, 2001).General well-being can be achieved through care on institutional or familial level. As the general well-being of an Asian elderly person is strongly associated with care at familial level (Itrat et al. 2007) we would, here, be confined to this sort of care. It is because of the fact that we intend to unveil the behaviour which lets a Pakistani woman provide geriatric care to the elderly.

The most widely recognized mechanism by which youths are bestowed zeal and enthusiasm to help and care others selflessly is their pro-social behaviour (Mattis et al., 2000). Pro-social behaviour comprises of actions such as helping, sharing, donating, cooperating, and volunteering which benefit society in common and other people in particular. Religious people are thought to be more pro-social than nonreligious ones. Religiosity (being actively involved in religion and spirituality) impacts the care-giving behaviour in a way that it generates the feelings of altruism, sympathy, helping and even the life sacrifice (Smith \& Denton, 2005).It not only provides youth (especially those who care their elderly in the family) with moral directives to lead their decisions but also proves to be a strong catalyst of care (Smith, 2003).

According to a survey on the elderly population of Pakistan, more than eighty percent of the elderly in Pakistan are dependent on their families, while more than two thirds of them live with their married sons. It means that most of the elderly in Pakistan are dependent upon their bahus (daughters-in-law) for their care (PMRC, 2005). But, a change in other aspects of life has also laid its impact on the care-giving behaviour of a Pakistani bahu. It's a general social phenomenon that a modern Pakistani care-giving woman, still a bahu (daughter-in-law), cares her kiddies more than the older dependents in the family (Mahajan and Ray, 2013). This deficit in her sociability demands its interpretation in religiosity perspectives. Although the socio-demographic factors like age of the care-giving woman, number of care-recipients in the family, span of her married life, employment status, household income and education etc. seem to be some of the 
predictors of quality care at familial level in Pakistan yet portraying a clear picture demands something more.

No doubt, some studies showing the impact of elderly individuals' personal involvement in religion and spirituality upon their well-being and depression have been conducted in recent past. Four of such studies conducted by George, Ellison, and Larson (2002); Kang and Kim (2011); Lee (2007) and Yoon (2006) suggested that religiosity plays a significant role in maintaining health of the elderly individuals. Similarly two studies conducted by Kang (2009) and Nelson-Becker (2005) focused upon coping of elderly with their stress. But unfortunately no study focusing upon the impact of religiosity on the behaviour of caregivers of institutional or familial domain has been conducted so far. The present study, in this way, has its own importance in the sense that it focuses not only the main socio-demographic factors as predictors of care but also the effect of religiosity on the care-giving behaviour of a Pakistani woman.

The researchers have selected Sargodha city to conduct this study. Sargodha is the main district of the Punjab province (Pakistan) that possesses an assembly of strong sociocultural norms especially with respect to women's behaviour in daily routine actions (Sathar and Kazi, 1997). The researchers kept in view the following objectives to conduct this research: i) How far socio-demographic factors (i.e. age of the care-giving woman, number of care-recipients in the family, span of her married life ,employment status, household income and education) affect Pakistani household women's care-giving behaviour towards senior individuals in the family, and ii) How far religiosity affects the Pakistani household women's care-giving behaviour towards senior individuals in the family.(iii)How do women of this area manage to enhance their religiosity.

\section{Methods}

The target population for this study consisted of those married women of age between 2150 years who have one or two elderly individuals residing with them and dependent upon them for their care. It was observed during the sampling pursuit that out of every 7 households, only 3 contained respondents of this study. Through multi-stage sampling method, a list of those women who have been living in the following areas of Sargodha city was prepared:

- Aziz Bhatti Town, Mianwali-Khushab Road;

- Iqbal Colony;

- Factory Area;

- Block X, New Satellite Town;

- Farooq Colony; and

- Isteqlalabad 
The list consisted of 2080 women. From this sampling frame a random sample, using table of random numbers, was drawn at $95 \%$ confidence level. The final realized sample included 208 women. Since a negligible number of women were Christians, therefore they were not included in the sample and consequently all the sample consisted of Muslim women only. Then after having verbal permission of the household head (usually their husbands), data was collected. The data for this study was collected during October 2012 to April 2013. As three women could not be contacted/intentionally avoided to respond, the data was collected from 205 women.

\section{Measure of Religiosity}

Data about the religiosity of the respondents was collected using Brief Multidimensional Measure of Religiosity/Spirituality (BMMRS). Of all the BMMRS sub-scales from, 5 most relevant to this study were adopted. The adopted sub-scales pertained to daily spiritual experiences, values/beliefs, forgiveness, private religious practice and religious support of the respondents.

According to Sun and Hun(2014), the sub-scale 'daily spiritual experiences' is meant to measure individuals' perceptions of the respondent about the existence of a transcendent being (i.e God in case of divine religions). A 5-point Likert scale, ranging from 1 (never) to 5 (every day), was used for this purpose. Cronbach's alpha for this study was 0.88 .

As for the 'value/beliefs', this sub-scale measures the extent to which an individual's behavior reflects a normative experience of the respondent's faith and religion. A 4-point Likert scale ranging from 1 (strongly disagree) to 4 (strongly agree) is used for this purpose (Sun and Hun, 2014). Cronbach's alpha for this study was 0.72 .

Similarly, 'forgiveness' means God's forgiveness is measured through 4-point Likert scale ranging from 1 (never) to 4 (always). (Sun and Hun, 2014). Cronbach's alpha for this study was 0.85 .

The sub-scale 'private religious practices' is measured on a 5-point Likert scale ranging from 1 (never) to 5 (everyday). (Sun and Hun, 2014). Cronbach's alpha for this study was 0.74 .

'Religious support', the last sub-scale for this study, is measured on a 4-point Likert ranging from 1 (none) to 4 (a great deal). (Sun and Hun, 2014). Cronbach's alpha for this study was 0.81 .

\section{Measure of General Well-being}

Data on general well-being (hereafter GWB) was collected through General Well-being Scale (GWS) the most suited scale for this study. Given by US Department of Health, 
Education and Welfare, this scale has been frequently used in numerous studies since 1977 (http://www.scalesandmeasures.net/ www.lasvegas.va.gov) and yielded good results. This scale comprises of 18 items measuring the extent of respondent's life satisfaction and level of psychological distress. There are 6 subscales measuring anxiety, depression, positive well-being, self-control, vitality, and general health. The total score runs from 0 to 110 with lower scores indicating more severe distress. The three cut-offs ranged 0-60 points for 'severe distress'; 61-72 points for 'moderate distress'; and 73-110 points for 'positive well-being'(http://www.parqol.com). Cronbach's alpha for this study was 0.90 .

To validate both the above instruments, a convenience sample of 20 women were taken to pre-test them.

\section{Data Analysis}

Data was analysed using SPSS-17.First descriptive analysis and then bivariate analysis consisting of hypothesis testing was conducted.

\section{Descriptive Analysis}

Descriptive analysis consisted of socio-demographic characteristics which included: age of the care-giving woman, number of care-recipients in the family, span of her married life, employment status, household income, education and GWB of the senior individuals under her care.

Table 1 provides a socio-demographic profile of the respondents. The results indicate that the highest percentage i.e. $53.2 \%$ of the respondents fall in the age range between 41 to 50 years. Almost all the respondents $(96.1 \%)$ have one care-recipient in the family. Slightly less than half of the respondents $(48.3 \%)$ consist of those who have spent their marriage life for 11 to 15 years. Most of the respondents $(95.1 \%)$ are un-employed whereas $56.6 \%$ have their average household income more than Rs.70, 000 per month. More than half of respondents i.e.50.2\% have their education at Intermediate level (i.e.FA/FSc). Majority of respondents (84.4\%) show medium-to-low level of religiosity. As far as GWB of the senior individuals under their care is concerned, a great majority $(84.9 \%)$ of the seniors are in a state of moderate-to-severe distress, indicative of least attention of their care-givers. 
Table: 1

Descriptive Analysis (Socio-demographic Characteristics)

\begin{tabular}{|l|c|c|}
\hline Items & Frequencies (\%) & P Value \\
\hline Age(years) & & $<.001$ \\
\hline $21-30$ & $41(20.0 \%)$ & \\
\hline $31-40$ & $55(26.8 \%)$ & \\
\hline $41-50$ & $109(53.2 \%)$ & \\
\hline No. of Care-Recipients in the Family & & $<.001$ \\
\hline One & $197(96.1 \%)$ & \\
\hline Two & $8(3.9 \%)$ & \\
\hline Span of Married Life(years) & & $<.001$ \\
\hline$<5$ & $33(16.1 \%)$ & \\
\hline $5-10$ & $64(31.2 \%)$ & \\
\hline $11-15$ & $99(48.3 \%)$ & \\
\hline $16-20$ & $7(3.4 \%)$ & \\
\hline$>20$ & $2(1.0 \%)$ & \\
\hline Employment Status & & $<.001$ \\
\hline Un-employed & $195(95.1 \%)$ & \\
\hline Employed & $10(4.9 \%)$ & \\
\hline Household Income(Pakistani Rupees) & & $<.001$ \\
\hline$<30,000$ & $23(11.2 \%)$ & \\
\hline $30,000-70,000$ & $66(32.2 \%)$ & \\
\hline$>70,000$ & $116(56.6 \%)$ & \\
\hline Education & & $<.001$ \\
\hline Illiterate & $4(2.0 \%)$ & \\
\hline Primary & $33(16.1 \%)$ & \\
\hline Matric & $52(25.4 \%)$ & \\
\hline FA/FSc & $103(50.2 \%)$ & \\
\hline BA/BSc & $13(6.3 \%)$ & \\
\hline General Well Being(GWB) & & \\
\hline Severe Distress(0-60) & $72(35.1 \%)$ & \\
\hline Moderate Distress(61-72) & $96(48.8 \%)$ & \\
\hline Positive Well Being(73-110) & $37(18.1 \%)$ & \\
\hline Religiosity & & \\
\hline Low(11-37) & $77(37.6 \%)$ & \\
\hline Medium(38-64) & $96(46.8 \%)$ & \\
\hline High(65-91) & $32(15.6 \%)$ & \\
\hline Total & $\mathbf{2 0 5}$ & \\
\hline & & \\
\hline
\end{tabular}




\section{Bi-variate Analysis:}

The analysis consisted of following two parts:

(1) General Well-being (GWB) and Socio-demographic Characteristics:

The results majorly consisted of seven hypotheses. Table 2 gives the linear regression results.

Table: 2

Summary of Bi-variate Analysis

\begin{tabular}{|l|c|l|l|}
\hline Null Hypotheses $\left(\mathbf{H}_{\mathbf{0}}\right)$ & $\operatorname{Beta}(\boldsymbol{\beta})$ & Sig. & Decision \\
\hline Hypothesis No.1 & 0.311 & $<0.05$ & Rejected \\
\hline Hypothesis No.2 & -0.094 & 0.182 & Accepted \\
\hline Hypothesis No.3 & 0.419 & $<0.05$ & Rejected \\
\hline Hypothesis No.4 & -0.023 & $<0.05$ & Rejected \\
\hline Hypothesis No.5 & 0.159 & $<0.05$ & Rejected \\
\hline Hypothesis No.6 & 0.102 & $<0.05$ & Rejected \\
\hline Hypothesis No.7 & 0.843 & $<0.05$ & Rejected \\
\hline
\end{tabular}

\section{Hypothesis Testing}

As is shown in Table 2, the following alternative hypotheses were tested against their null hypotheses to accept or reject different claims regarding GWB as related to the sociodemographic characteristics of the care-giving women.

\section{Hypothesis No. 1: GWB and the Care-giving Woman's Age}

$\mathbf{H}_{\mathbf{0}}$ : GWB is not significantly related with the care-giving woman's age.

$\mathbf{H}_{\mathbf{1}}$ : GWB is significantly related with the care-giving woman's age.

The structural coefficient shows that there is a significant positive relationship between GWB and the care-giving woman's age $(\beta=0.311, \mathrm{p}<0.05)$.Hence, we reject the null hypothesis against the alternative hypothesis. It means that age of a woman has a significant impact on her care-giving behaviour. Seasoned and mature women are likely to be more caring than their younger counterparts.

\section{Hypothesis No. 2: GWB and No. of Care-Recipients in the Family}

$\mathbf{H}_{\mathbf{0}}$ : GWB is not significantly related with no. of the care-recipients in the family. $\mathbf{H}_{2}$ : GWB is significantly related with no. of the care-recipients in the family.

The structural coefficient shows that there is an insignificant negative relationship between GWB and the no. of the care-recipients in the family $(\beta=-0.094, p>0.05)$. Hence, we accept the null hypothesis against the alternative hypothesis. It means that no. of care-recipients present in the family has no significant impact on the care-giving behaviour of a woman. 

the Family: A Case of Sargodha City (Pakistan)

\section{Hypothesis No. 3: GWB and the Care-giving Woman's Span of Married Life} $\mathbf{H}_{\mathbf{0}}$ : GWB is not significantly related with the care-giving woman's span of married life. $\mathbf{H}_{3}$ : GWB is significantly related with the care-giving woman's span of married life. The structural coefficient shows that there is a significant positive relationship between GWB and the care-giving woman's span of married life $(\beta=0.419, \mathrm{p}<0.05)$.Hence, we reject the null hypothesis against the alternative hypothesis. It means that a woman's span of married life has a significant impact on her care-giving behaviour. Longer span of married life is one of the signs of more compromise with the norms of the in-laws' family.

\section{Hypothesis No. 4: GWB and the Care-giving Woman's Employment Status}

$\mathbf{H}_{\mathbf{0}}$ : GWB is not significantly related with the care-giving woman's employment status.

$\mathbf{H}_{4}$ : GWB is significantly related with the care-giving woman's employment status.

The structural coefficient shows that there is a significant negative relationship between GWB and the care-giving woman's employment status $(\beta=-0.023, \mathrm{p}<0.05)$. Hence, we reject the null hypothesis against the alternative hypothesis. It means that a woman's employment status has an adverse impact on her care-giving behavior. An employed woman cannot spare much time to regularly look after the elderly person(s) under her care.

\section{Hypothesis No. 5: GWB and the Care-giving Woman's Household Income}

$\mathbf{H}_{\mathbf{0}}$ : GWB is not significantly related with the care-giving woman's household income.

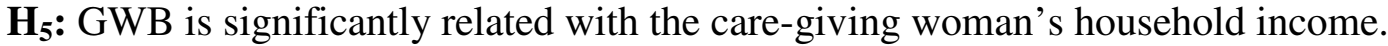

The structural coefficient shows that there is a significant positive relationship between GWB and the care-giving woman's household income $(\beta=0.159, p<0.05)$. Hence, we reject the null hypothesis against the alternative hypothesis. It means that a woman's household income has a significant impact on her care-giving behaviour. Resourceful women are supposed to spare more resources for the care of their dependents.

\section{Hypothesis No.6: GWB and the Care-giving Woman's Education}

$\mathbf{H}_{\mathbf{0}}$ : GWB is not significantly related with the care-giving woman's education.

$\mathbf{H}_{6}$ : GWB is significantly related with the care-giving woman's education.

The structural coefficient shows that there is a significant positive relationship between GWB and the care-giving woman's education $(\beta=0.102, \mathrm{p}<0.05)$. Hence, we reject the null hypothesis against the alternative hypothesis. It means that a woman's education has significant impact on her care-giving behaviour. Lack of education can be a constraint.

\section{Hypothesis No. 7: GWB and the Care-giving Woman's Religiosity}

$\mathbf{H}_{\mathbf{0}}$ : GWB is not significantly related with the care-giving woman's religiosity. $\mathbf{H}_{7}$ : GWB is significantly related with the care-giving woman's religiosity.

The structural coefficient shows that there is a significant relationship between GWB and the care-giving woman's religiosity $(\beta=0.843, \mathrm{p}<0.05)$.Hence, we reject the null 
hypothesis against the alternative hypothesis. It means that a woman's religiosity has a significant impact on her care-giving behaviour. Religious women are thought to be more pro-social than nonreligious ones.

\section{(2)Determinants of Religiosity:}

As mentioned above, following six factors determine religiosity of an Asian woman: (i)daily spiritual experiences, (ii)values/beliefs,(iii) forgiveness,(iv) private religious practices,(v) religious support, and(vi) religious course(s) attended.

Correlation statistics of religiosity with these variables, shown in Table 3, illustrates the direction and strength of linear relationship between two variables. The relationships between the dependent variable religiosity and independent variables such as daily spiritual experiences, value/beliefs, forgiveness, private religious practices, religious support and religious course(s) attended has been shown in the table. All the independent variables, except religious course(s) attended, were the dimensions of religiosity adopted for this study. We witness a positive and significant correlation of religiosity with all the variables except the forgiveness. The variables daily spiritual experiences, value/beliefs, and the private religious practices are more strongly correlated with religiosity ( $\mathrm{r}=0.540$, $\mathrm{r}=0.647$ and $\mathrm{r}=0.623$ ) than those of religious support and religious course(s) attended(r=0.209 and $\mathrm{r}=0.157)$.

Table: 3

Correlation Statistics of Religiosity Dimensions

\begin{tabular}{|l|l|l|l|l|l|l|l|}
\hline Variables & $\mathbf{1}$ & $\mathbf{2}$ & $\mathbf{3}$ & $\mathbf{4}$ & $\mathbf{5}$ & $\mathbf{6}$ & $\mathbf{7}$ \\
\hline $\begin{array}{l}\text { Daily Spiritual } \\
\text { Experiences }\end{array}$ & 1.000 & & & & & & \\
\hline Values/Beliefs & $.346^{* * *}$ & 1.000 & & & & & \\
\hline Forgiveness & .095 & .082 & 1.000 & & & & \\
\hline Private Religious Practices & $.389^{* *}$ & $.401 * *$ & .046 & 1.000 & & & \\
\hline Religious Support & $.188^{* *}$ & .133 & .100 & .126 & 1.000 & & \\
\hline Religious Course(s) & -.053 & .043 & .049 & .060 & $.193^{* *}$ & 1.000 & \\
\hline Religiosity & $.540^{* *}$ & $.647^{* *}$ & .131 & $.623^{* *}$ & $.209^{* *}$ & $.157^{*}$ & 1.000 \\
\hline Total Cases & $\mathbf{2 0 5}$ & & & & & & \\
\hline
\end{tabular}

** Correlation is significant at the 0.01 level (2-tailed).

* Correlation is significant at the 0.05 level (2-tailed).

Beside this, it also shows the correlation among independent variables. From the table it can be seen that daily spiritual experiences is correlated with three variables: values/beliefs, private religious practices, and religious support. One the other hand, values/beliefs is correlated with private religious practices and religious support is correlated with religious course(s) attended. 

the Family: A Case of Sargodha City (Pakistan)

\section{Discussions}

To our knowledge, this is the first study that demonstrates the effect of religiosity on the care-giving behaviour towards the senior individuals in the family. The findings of the study indicate that a large fraction of the sample comprises of mature women (41-50 years old), with moderate span of their married life (11-15years).This is particular with Pakistani culture that the bahus (daughters-in-law) automatically tune-up themselves to care the older adults in the family as the years pass. But, strange enough that a great majority of senior individuals in the family (84.9\%) are in a state of low well-being (a measure of care). We were to reveal whether this low well-being was due to the lack of religiosity on the part of care-givers or not. The major findings of the study supported the idea that religiosity is one of the greatest factors positively associated with wellbeing $(r=0.843, p<.05)$.Among the other factors, age, span of married life, household income and education correlate with the well-being positively but employment status negatively. Very interestingly, as the findings indicate, the care-giving behaviour is irrespective of the number of care-recipients in the family.

Now, where does religiosity of a care-giving Pakistani woman come from? The findings vivaciously answer that religiosity of a Pakistani women is determined majorly by her daily spiritual experiences, cultural values and her private religious practices. The second slot factors can be religious support from others and religious course(s) attended by her.

\section{Conclusions and Recommendations}

The quality of life for elderly people enhanced if the care-giver is zealous and enthusiastic. One's being so is only possible if one is highly pro-social. Various other factors that promote pro-social behaviour of the care-givers have been explored but religiosity remained unexplored. This study was designed for that. We, through this study, have reached the conclusion that religiosity affects pro-social (care-giving) behaviour of Pakistani women to the great extent. Based on the findings, the following recommendations are made: i) Media, especially electronic, can play its role to promote geriatric care at home through religiosity. ii) Your caring efforts at home must be integrated with the health and social care programmes at national level. iii) Not only the religiosity the caring women given should also be equipped with caring skills and necessary provisions. iv) Government should encourage, facilitate and supervise geriatric care at familial level. v) Ensure that research in care and treatment does not exclude older people.

\section{References}

Birren, James E. \& Shaie, K. Warner (eds.). (1985). Handbook of the Psychology of Aging, New York: Van Nostrand Reinhold. 
Cole, T. R., \& Winkler, M. G., (eds.). (1994). The Oxford Book of Aging. New York: Oxford University Press.

George, L. K., Ellison, C. G. \& Larson, D. B. (2002). Target Article: Explaining the Relationships between Religious Involvement and Health, Psychological Inquiry, vol.13, pp.190-200.

Govt. of Pakistan. (2005). Survey on the Health and Living Conditions of the Elderly Population of Pakistan, Islamabad: Pakistan Medical Research Council

http://www.parqol.com Retrieved online on November 2013

http://www.scalesandmeasures.net Retrieved online on November 2013

Isaacowitz, D. (2005). Correlates of Well-Being in Adulthood and Old Age: A Tale of Two Optimisms, J Res Personal, vol.39, pp.224-244.

Itrat, A., Taqai, A. M., Qazi, F., \& Qidwai, W. (2007). Family Systems: Perceptions of Elderly Patients and their Attendants Presenting at a University Hospital in Karachi, Pakistan. Journal of Pakistan Medical Association, vol.57:2, pp.106-109.

Kang, S. (2009). The Effects of Self-Efficacy and Social Support on the Quality of Life of the Elderly with Depression, Journal of the Korean Gerontological Society: vol.29, pp.629-643.

Kang, S., \& Kim, H. (2011). A Study of Impact of Social Activities and Religion/ Spirituality on Depression and Life Satisfaction among the Korean elderly, The Population Association of Korea, vol.34, pp.163-190.

Lee, E. O. (2007). Religion and Spirituality as Predictors of Well-Being among Chinese American and Korean American older adults. Journal of Religion, Spirituality Aging, vol.19, pp.77-100.

Mahajan, Abhimanyu and Ray, Anushree.(2013). The Indian Elder: Factors Affecting Geriatric Care in India. Global Journal of Medicine and Public Health, vol.4:2.

Mattis J. S., Jagers R. J., Hatcher C. A., Lawhon G. D., Murphy E. J. \& Murray Y. F. (2000). Religiosity, Volunteerism, and Community Involvement among African American men: An Exploratory Analysis. Journal of Community Psychology, vol.28:4, pp.391-406 

the Family: A Case of Sargodha City (Pakistan)

Nelson-Becker, H. (2005). Religion and Coping in Older Adults: A Social Work Perspective. Journal of Gerontological Social Work: vol.45, pp.51-67.

Noelker, L. S., and Harel, Z. (2001). Linking Quality of Long-Term Care and Quality of Life. New York: Springer Publishing Company.

Sathar, Zeba Ayesha and Shahnaz Kazi, (1997). Pakistan. Female Autonomy in Rural Punjab. Islamabad: PIDE (Pakistan Institute of Development Economics)

Smith, C. (2003). Theorizing Religious Effects among American Adolescents, Journal for the Scientific Study of Religion: vol.42:1, pp.17-30.

Smith, C. and Denton, M. L. (2005). Soul Searching: The Religious and Spiritual Lives of American Teenagers. New York: Oxford University Press

Sun Kyung Kang \& Hun Jin Kim.(2014). Reflections on the Recovery Paradigm Using Religion/ Spirituality for Korean Elderly Adults: Depression and Well-Being in Life. Asia Pacific Journal of Social Work and Development, vol.24:1-2, pp.59-70.

Wei, Jeanne Y. \& Levkoff, Sue. (2000). Aging Well: The Complete Guide to Physical and Emotional Health. New York: John Wiley and Sons.

www.lasvegas.va.gov/Documents/General_Wellbeing_Scale.pdf Retrieved online on November 2013

www.wikipedia.com Retrieved online on January 2014

Yoon, D. P. (2006). Factors affecting subjective weil-being for rural elderly individuals. Journal of Religion Spirituality in Social Work: Social Thought: vol.25, pp.59-75.

Dr. Mohammad Iqbal is Assistant Professor in the Department of Social Work, University of Sargodha.

Dr. Syeda Mehnaz Hassan is Assistant Professor in the Department of Social Work, University of the Punjab. 